\title{
The PAGES Early-Career Network
}

\author{
PAGES ECN Steering Committee ${ }^{1}$
}

Early-career researchers (ECRs) bring fresh and novel ideas that have the potential to contribute to existing knowledge and challenge established paradigms. Intense competition in the current job market coupled with challenges such as establishing a professional identity, competing for grants, and choosing an independent career path are leading to a small success rate of ECRs within academia. Therefore, the greater scientific community is missing out on new research ideas, concepts and collaborations when ECRs are lost through the academic bottleneck effect. So how can we maintain a pool of strong-minded ECRs in academia?

One possible answer is establishing a supportive network of researchers that are at the same stages in their careers. So, to facilitate the career of ECRs, the PAGES Early-Career Network (ECN) was created. This idea was first discussed in 2017 at the 3rd Young Scientists Meeting (YSM) in Morillo de Tou, Spain, and resonated with a group of enthusiastic participants. Nested within the PAGES and Future Earth communities (Fig. 1), the goal of the PAGES ECN is to aid in the dissemination of information, establish scientific networks, and foster the development of ideas that can lead to future research collaborations and improved job prospects. Developed by early-career researchers for early-career researchers, the overarching aim of the PAGES ECN is to facilitate the exchange of ideas and skill sets that will provide the tools necessary for researchers to excel in their fields.

The PAGES ECN will achieve this aim by cre ating a skills database platform where ECRs will be able to meet and share experiences and create ideas for new research and international collaborations. Additionally, the PAGES ECN will foster career development and improve skill sets of ECRs via webinars and training events that will be tailored to the needs of the network participants. The PAGES ECN will promote education and outreach to disseminate scientific ideas to a wider audience and improve the visibility of ECRs in the scientific community by collaborating with other early-career networks.

The interactiveness of the PAGES ECN means any member can participate and work alongside the steering committee, and contribute to the organization of webinars and workshops, as well as participate in outreach events such as the ECN blog and social media platforms. We also seek participation among active members who are interested in acting as regional ECN representatives to facilitate the global integration of ECRs into the wider scientific community. To

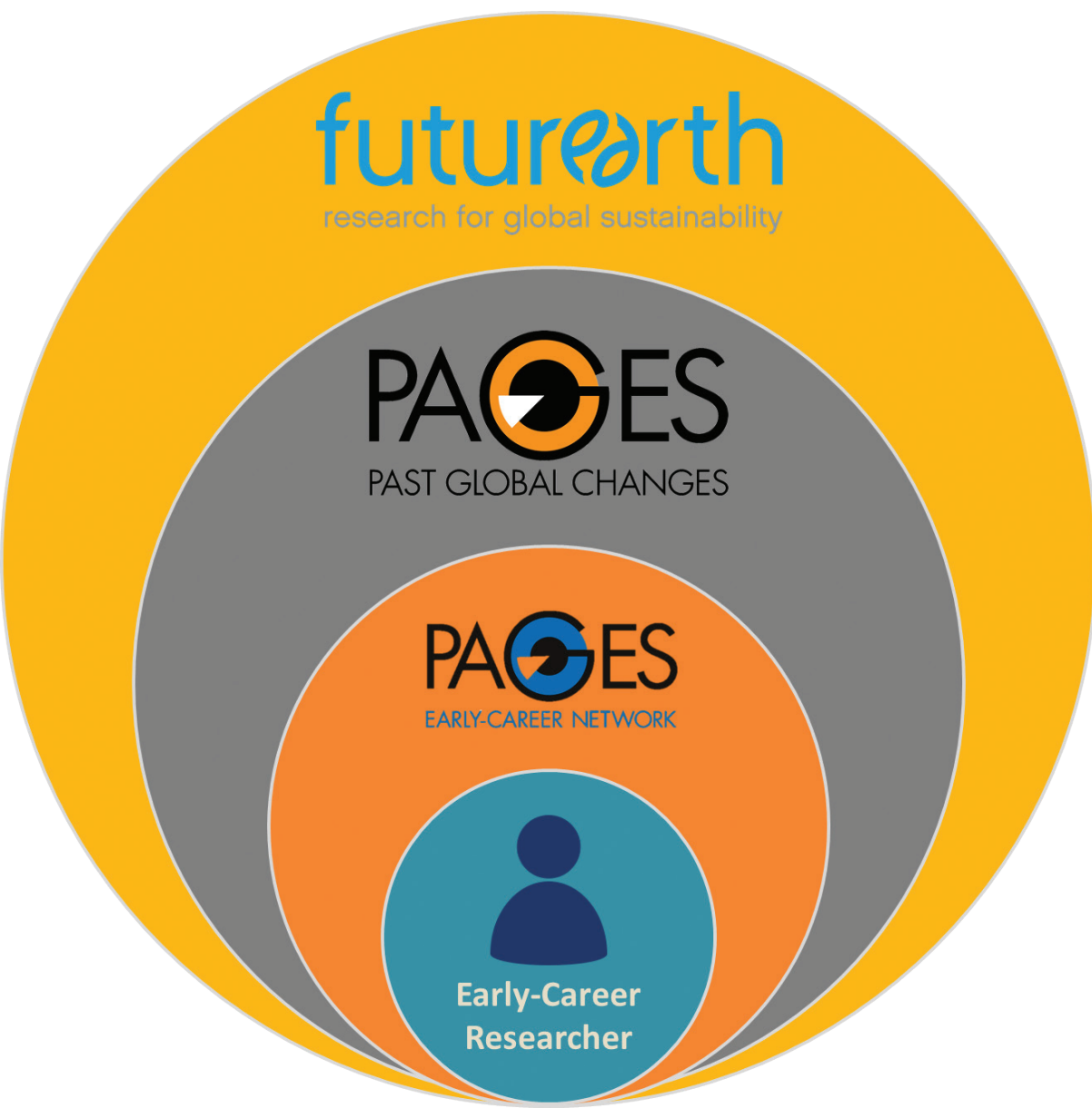

Figure 1: Structure of the PAGES ECN within the PAGES and Future Earth communities.

strengthen the position of ECRs within the PAGES community, members of the ECN steering committee will work with PAGES working groups to nominate a liaison person between them.

Visit the PAGES ECN website http://pastglobalchanges.org/ecn, where you can also sign up to become a member. Also subscribe to the mailing list to keep up to date with our activities. ECRs are encouraged to contribute to The Early Pages blog (https:// theearlypages.blogspot.ch). You may also contact the PAGES ECN at pages.ecn@gmail. com and follow us on Twitter (@PAGES_ECN) and Facebook (www.facebook.com/PAGES. ECN), and watch our videos on our Youtube channel (https://www.youtube.com/channel/ UCnDs_RxOvXZ3nGG6Omm16qA).

\section{Activities}

One month after the network's February 2018 launch, the committee organized a pair of webinars entitled 'Welcome to the PAGES $E C N^{\prime}$ to introduce the group to the PAGES and paleoscience communities. The first in-person meeting of the PAGES ECN was held at the European Geosciences Union (EGU) meeting in Vienna, Austria, in April 2018. During this splinter meeting, we also introduced the PAGES ECN to interested ECRs. The main goal of this meeting was to exchange directly with other ECRs, get feedback and ideas about this new network, and encourage future collaboration. Future activities will be posted on the website, Twitter and Facebook.

\section{AFFILIATIONS}

'V. Carter (Charles University, Czech Republic); S. Alexandroff (Bangor University, UK); X. Benito (University of Nebraska-Lincoln, USA); A. Bonk (Polish Academy of Sciences, Poland); M. Chevalier (University of Lausanne, Switzerland); A. Kay (University of Lausanne, Switzerland); A. Koch (University College London, UK); S.Y. Maezumi (University of Exeter, UK); N. Schafstall (Czech University of Life Sciences, Czech Republic); T. Trofimova (Uni Research, Bjerknes Centre for Climate Research, Norway).

\section{CONTACT}

PAGES.ECN@gmail.com 